16. 河部 靖, 鈴井恒孝, 井口正通 : アルキル化フラン誘導体の研究 (第 5 報*1)

5-Nitro-2-furaldehyde 4-Alkylsemicarbazone 㐨よび 4-Alkylthiosemicarbazone の合成並びに抗微生物性*2

Kiyoshi Kawabe, Tsunetaka Suzui, and Masamichi Iguchi : Studies on Alkylated Furan Derivatives. V. Synthesis and Antimicrobial Activity of 5-Nitro2-furaldehyde 4-Alkylsemicarbazone and 4-Alkylthiosemicarbazone.

(Research Laboratory, Showa Yakuhin Kako Co., Ltd.*3)

As the alkylated derivatives of 5-nitrofuran and its allied compounds, 5-nitro-2-furaldehyde 4-alkylsemicarbazone and 4-alkylthiosemicarbazones were prepared. None of these compounds showed antitubercular activity but some of the compounds had growth-inhibitory action against Trichophyton and Microsporum spp. at low concentration. None of the compounds were effective against Candida and Saccharomyces.

(Received June 6, 1959)

5-nitro-2-furaldehyde semicarbazone (nitrofurazone) (I) および thiosemicarbazone (II)のアルキル誘 導体は殆んど知られていない。著者等は（I）拈よび（II）のアルキル誘導体である 5-nitro-2-furaldehyde 4alky!semicarbazone (III) ならびに 4-alkylthiosemicarbazone (IV) に着目し，これらを合咸した。

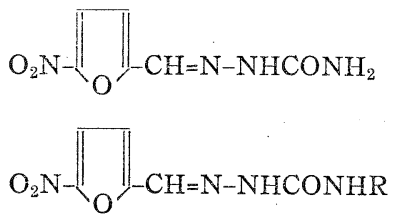

$$
\mathrm{R}=\text { alkyl }
$$

nitrofurazone のアルキル誘導体として Gever 等1) は Chart 1 に示す反応工程により $\mathrm{C}_{2} \mathrm{H}_{5} \sim \mathrm{C}_{5} \mathrm{H}_{11}$ のアル キル基を有する 5-nitro-2-furaldehyde 2-alkylsemicarbazone（V)を合成したことを報告している.

Chart 1.

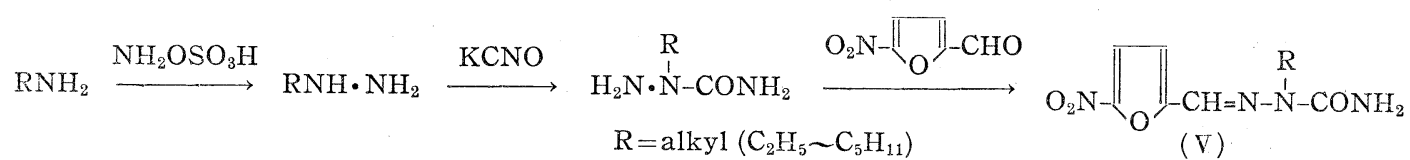

然るに（III）を合成した報告は見られない（III）を合成するには Chart 2 の如く 5-nitro-2-furaldehyde (VI) またはその diacetate に 4-alkylsemicarbazide (VII) を縮合せしめるのが常法と考えられる.

Chart 2.

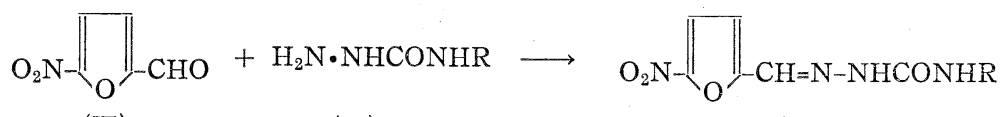

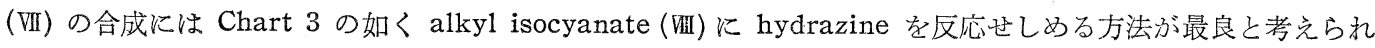
るが (VIII) は水と接触した場合に容易に分解する性質があるので反応系に含水ヒドラジンを使用できない不便があ る・したがつて著者等は（VII）の合成法を検討した結果, 反応工程は長いが Chart 4 亿示した方法により(VII)を 合成するのが適当であることを見出した。

*1 第 4 報 : 本誌 $80,62(1960)$.

*3 Minami-rokugo, Ota-ku, Tokyo.

*2 一部は第79回日本薬学会年会で発表 (1959).

1) G. Gever, K. Hayes : J. Org. Chem. 14, 813(1949). 
Chart 3.

$\mathrm{RNCO}+\mathrm{NH}_{2} \cdot \mathrm{NH}_{2}$

(VIII)
$\mathrm{RNHCONH} \cdot \mathrm{NH}_{2}$

(VII)

Chart 4.

(IX) $\stackrel{\text { elect. reduction }}{\longrightarrow} \mathrm{RNHCONH} \cdot \mathrm{NH}_{2}$

(VII)

すなわち nitrourea (IX) より alkylurea (X) の製法は Davis 等 ${ }^{2}$ おょび Werner ${ }^{3)}$ （X) より 1-alkyl-3nitrourea (XI) は Davis 等4) の合成法を応用した。(XI) のニトロ基の還元は著者等が検討した結果, 電解還元 が至当であることを認めた. 但し octy1 以上のアルキル基を有する化合物の還元は困難であつたため高級アルキ ル基を有する (III) は得られなかつた。(VI) 拈よびその diacetate の合成に関しては既に Gilman 等5) または西 海枝等 ${ }^{6}$ の詳細な報告が見られる５-nitro-2-furaldehyde は不安定なため合成原料としてはその diacetate を 用いる方が得策である.

(IV) の合成は大体 (III) の場合と同様に操作することも考えられるが縮合に用いる 4-alkylthiosemicarbazide (XII) が (VII) よりも簡単に得られるため (IV) は (III) に比較して合成は容易である。すなわち (IV) を得る反応工 程を Chart 5 に示す.

\section{Chart 5.}

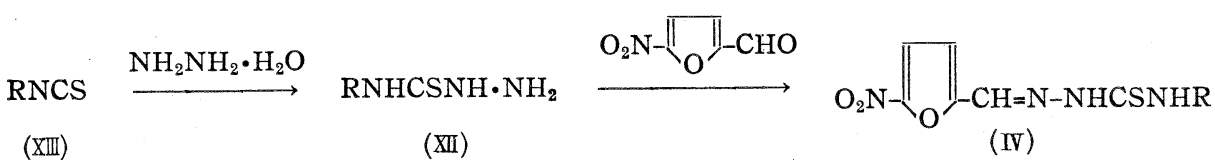

alkyl isothiocyanate (XII) は Dyson ${ }^{7)}$, Frentzel ${ }^{8)}$, Delépine ${ }^{9}$, Moore 等10) の合成法で得られ，かつこれは 水に対し安定であるため Cattelain ${ }^{11)}$ または Bernstein 等 ${ }^{12)}$ の報告にしたがい含水ヒドラジンを反応せしめる ことにより容易に（XII）が得られた。これに（VI）を縮合せしめて（IV）を合成した。

以上の如く合成した（III）怙よび（IV) の抗結核性ならびに抗かび性につき試験した結果をそれぞれ Table I, III に示す, 被検菌ならびに試験方法は第 1 報 ${ }^{13)}$ に報告したところに準じて実施した.

Table I. Antibacterial Activity of 5-Nitro-2-furaldehyde 4-Alkylsemicarbazone and 4-Alkylthiosemicarbazone against Mycobacterium tuberculosis $\mathrm{H}_{37} \mathrm{Rv}$

(1) 5-Nitro-2-furaldehyde 4-alkylsemicarbazone

$\mathrm{O}_{2} \mathrm{~N}-\|_{\mathrm{O}}^{\|}-\mathrm{CH}=\mathrm{N}-\mathrm{NHCONHR}$

$\begin{array}{ccccccccc}\text { No. } & \mathrm{R} & \mathrm{MIC}(M) & \mathrm{No} & \mathrm{R} & \mathrm{MIC}(M) & \text { No. } & \mathrm{R} & \mathrm{MIC}(M) \\ 1 & \mathrm{C}_{2} \mathrm{H}_{5} & 5 \times 10^{-4} & 4 & \mathrm{C}_{4} \mathrm{H}_{9} & >10^{-3} & 7 & \mathrm{C}_{7} \mathrm{H}_{16} & >10^{-3} \\ 2 & \mathrm{C}_{3} \mathrm{H}_{7} & >10^{-3} & 5 & \text { iso- } \mathrm{C}_{4} \mathrm{H}_{9} & >10^{-3} & & & \\ 3 & \text { iso- } \mathrm{C}_{3} \mathrm{H}_{7} & >10^{-3} & 6 & \mathrm{C}_{6} \mathrm{H}_{13} & >10^{-3} & & & \end{array}$

2) T. L. Davis, K. C. Blanchard: J. Am. Chem. Soc. 51, 1797(1929).

3) E. A. Werner : J. Chem. Soc. 115, 1101(1919).

4) T. L. Davis, N. D. Constan : J. Am. Chem. Soc. 58, 1800(1936).

5) H. Gilman, G. F. Wright: Ibid. 52, 2551(1930).

6) 西海枝, 木村：本誌 73, 1132(1953).

7) G. M. Dyson, R.F. Hunter : Rec. trav. chim. 45, 421(1926).

8) J. Frentzel: Ber. 16, 746(1886). $\quad$ 9) M. Delépine : Compt. rend. 144, 1126(1906).

10) M. L. Moore, F. S. Crossley : “'Org. Syntheses ”, 21, 81.

11) E. Cattelain : Bull. soc. chim. France 11, 249(1944).

12) J. Bernstein, H. L. Yale: J. Am. Chem. Soc. 73, 906(1951).

13) 河部, 鈴井, 井口：本誌 80, 50(1960). 
(2) 5-Nitro-2-furaldehyde 4-alkylthiosemicarbazone

$\begin{array}{rrrrrrrrr}1 & \mathrm{H} & >10^{-3} & 6 & \text { iso- } \mathrm{C}_{4} \mathrm{H}_{9} & 10^{-4} & 11 & \mathrm{C}_{12} \mathrm{H}_{25} & 5 \times 10^{-5} \\ 2 & \mathrm{CH}_{3} & 5 \times 10^{-5} & 7 & \mathrm{C}_{5} \mathrm{H}_{11} & 5 \times 10^{-5} & 12 & \mathrm{C}_{14} \mathrm{H}_{29} & 10^{-3} \\ 3 & \mathrm{C}_{2} \mathrm{H}_{5} & 5 \times 10^{-5} & 8 & \mathrm{C}_{6} \mathrm{H}_{13} & 5 \times 10^{-4} & & & \\ 4 & \mathrm{C}_{3} \mathrm{H}_{7} & 5 \times 10^{-5} & 9 & \mathrm{C}_{8} \mathrm{H}_{17} & 5 \times 10^{-4} & \text { Nitrofurazone } & >10^{-3} \\ 5 & \mathrm{C}_{4} \mathrm{H}_{9} & 5 \times 10^{-5} & 10 & \mathrm{C}_{10} \mathrm{H}_{21} & 5 \times 10^{-5} & \text { INAH } & 10^{-6}\end{array}$

Table II. Antifungal Activity of 5-Nitro-2-furaldehyde 4-Alkylsemicarbazone and 4-Alkylthiosemicarbazone against Various Fungi

(1) 5-Nitro-2-furaldehyde 4-alkylsemicarbazone $\mathrm{O}_{2} \mathrm{~N}-\|_{\mathrm{O}}-\mathrm{CH}=\mathrm{N}-\mathrm{NHCONHR} \operatorname{MIC}(M)$

$\begin{array}{cccc}\overbrace{\text { No. }}^{\text {Compound }} & \text { Strain } & \begin{array}{c}\text { Can. } \\ \text { albicans }\end{array} & \begin{array}{c}\text { Sac. } \\ \text { cerevisiae }\end{array} \\ 1 & \mathrm{C}_{2} \mathrm{H}_{5} & >10^{-3} & >10^{-3} \\ 2 & \mathrm{C}_{3} \mathrm{H}_{7} & >10^{-3} & >10^{-3} \\ 3 & \text { iso- } \mathrm{C}_{3} \mathrm{H}_{7} & >10^{-3} & >10^{-3} \\ 4 & \mathrm{C}_{4} \mathrm{H}_{9} & >10^{-3} & >10^{-3} \\ 5 & \text { iso- } \mathrm{C}_{4} \mathrm{H}_{9} & >10^{-3} & >10^{-3} \\ 6 & \mathrm{C}_{6} \mathrm{H}_{13} & 10^{-4} & >10^{-3} \\ 7 & \mathrm{C}_{7} \mathrm{H}_{16} & 10^{-3} & >10^{-3}\end{array}$

(2) 5-Nitro-2-furaldehyde 4-alkylthiosemicarbazone

\begin{tabular}{|c|c|c|c|c|c|c|}
\hline 1 & $\mathrm{H}$ & $>10^{-3}$ & $>10^{-3}$ & $10^{-3}$ & $10^{-3}$ & $10^{-5}$ \\
\hline 2 & $\mathrm{CH}_{3}$ & $>10^{-3}$ & $10^{-3}$ & $10^{-3}$ & $10^{-3}$ & $10^{-3}$ \\
\hline 3 & $\mathrm{C}_{2} \mathrm{H}_{5}$ & $>10^{-3}$ & $>10^{-3}$ & $>10^{-3}$ & $10^{-3}$ & $10^{-3}$ \\
\hline 4 & $\mathrm{C}_{3} \mathrm{H}_{7}$ & $10^{-3}$ & $>10^{-3}$ & $10^{-3}$ & $10^{-5}$ & $10^{-4}$ \\
\hline - 5 & $\mathrm{C}_{4} \mathrm{H}_{9}$ & $10^{-4}$ & $>10^{-3}$ & $10^{-3}$ & $10^{-6}$ & $10^{-6}$ \\
\hline 6 & iso- $\mathrm{C}_{4} \mathrm{H}_{9}$ & $10^{-3}$ & $>10^{-3}$ & $10^{-3}$ & $10^{-5}$ & $01^{-6}$ \\
\hline 7 & $\mathrm{C}_{5} \mathrm{H}_{11}$ & $10^{-4}$ & $>10^{-3}$ & $10^{-4}$ & $10^{-7}$ & $10^{-7}$ \\
\hline 8 & $\mathrm{C}_{6} \mathrm{H}_{13}$ & $10^{-4}$ & $>10^{-3}$ & $10^{-4}$ & $10^{-7}$ & $10^{-7}$ \\
\hline 9 & $\mathrm{C}_{8} \mathrm{H}_{17}$ & $>10^{-3}$ & $>10^{-3}$ & $10^{-4}$ & $10^{-6}$ & $10^{-7}$ \\
\hline 10 & $\mathrm{C}_{10} \mathrm{H}_{21}$ & $>10^{-3}$ & $>10^{-3}$ & $10^{-3}$ & $10^{-5}$ & $10^{-7}$ \\
\hline 11 & $\mathrm{C}_{12} \mathrm{H}_{25}$ & $>10^{-3}$ & $>10^{-3}$ & $>10^{-3}$ & $10^{-5}$ & $10^{-6}$ \\
\hline 12 & $\mathrm{C}_{14} \mathrm{H}_{29}$ & $>10^{-3}$ & $>10^{-3}$ & $>10^{-3}$ & $10^{-5}$ & $10^{-5}$ \\
\hline \multicolumn{2}{|c|}{ Nitrofurazone } & $10^{-3}$ & $10^{-3}$ & $>10^{-3}$ & $10^{-6}$ & $10^{-5}$ \\
\hline \multicolumn{2}{|c|}{ Gentian violet } & $10^{-5}$ & $10^{-4}$ & $10^{-4}$ & $10^{-5}$ & $10^{-5}$ \\
\hline
\end{tabular}

Table I によれば (III) の中に抗結核性化合物は見られない（IV) では抗結核性化合物は若干見られるが抗菌 力は余り強くない. またアルキル基による抗菌力の差も明らかでない.

(III) 特よび（IV）の抗かび性は Table II に示す如くTrichophyton 括よび Microsporum に対し強い発育阻 止作用が見られ，フルキル基の影響は（III）では明らかでないが（IV）では中級アルキル基を有する化合物の抗か び性がすぐれていると思われる.（III）の中で $\mathrm{C}_{6} \mathrm{H}_{13}$ のアルキル誘導体が比較的 Asp. niger の発育を抑制するこ とを見出したが，それ以外に(III)，(IV) の中で Candida, Saccharomyces 特よび Aspergillus に対し有効な化 合物は見られなかつた。

\section{実 験 $の$ 部}

5-Nitro-2-furaldehyde 4-alkylsemicarbazone (Table III) 底面積 $35 \mathrm{~cm}^{2}$ の電解槽に陽極としてコイ ル状 $\mathrm{Pb}$ 板，陰極として Hg を使用し，陽極は円筒隔膜内に設置する。この電解槽内部に $20 \% \mathrm{H}_{2} \mathrm{SO}_{4}$ を陰極 液として 50〜70 cc，陽極液として約 $20 \mathrm{cc}$ 入れる. 陰極液内に攪挥しながら 1-alkyl-3-nitrourea $0.03 \mathrm{~mol}$ を少量ずつ加えて還元を行なう。この間内温が $10^{\circ}$ 以下に保たれるよう外部より氷冷すること特よび電解時の電 流密度が 0.06 ～ $0.07 \mathrm{~A} / \mathrm{cm}^{2}$ に保たれるよう電流を調整することが必要である. 添加後 5〜6 hr 前記の条件で還 元を継続する，生成した 4-alkylsemicarbazide $\mathrm{H}_{2} \mathrm{SO}_{4}$ 塩はアルキル基が高級になるにしたがい難溶となり，か つ泡立ちが激しい.この場合は適量の EtOH を加えて調整する. 還元終了後, 少量の不溶物あればこれを沪去し 
た後，汇液に 5-nitro-2-furaldehyde diacetate ${ }^{5,6)} 5.8 \mathrm{~g}(0.024 \mathrm{~mol})$ を EtOH 70〜80 cc に溶解した液を加え， 水浴上で 70〜80 に $30 \mathrm{~min}$ 還流加熱. ついで強冷すれば 5-nitro-2-furaldehyde 4-alkylsemicarbazone の 粗結晶が析出. これを沪取, dil EtOH より再結晶.

Table III. 5-Nitro-2-furaldehyde 4-Alkylsemicarbazone

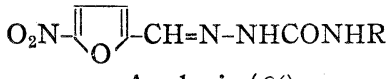

$\begin{array}{lrcccc}\text { No. } & \mathrm{R} & \text { Formula } & \text { m.p. }\left({ }^{\circ} \mathrm{C}\right) & \text { Appearance } & \begin{array}{c}\text { Yield } \\ (\%)\end{array} \\ & & & & & \\ 1 & \mathrm{C}_{2} \mathrm{H}_{5} & \mathrm{C}_{8} \mathrm{H}_{10} \mathrm{O}_{4} \mathrm{~N}_{4} & 187 \text { (decomp.) } & \text { yellow needles } & 65 \\ 2 & \mathrm{C}_{3} \mathrm{H}_{7} & \mathrm{C}_{9} \mathrm{H}_{12} \mathrm{O}_{4} \mathrm{~N}_{4} & 170 \sim 171 & \text { " } & 51 \\ 3 & \text { iso- } \mathrm{C}_{3} \mathrm{H}_{7} & \mathrm{C}_{9} \mathrm{H}_{12} \mathrm{O}_{4} \mathrm{~N}_{4} & 205 \text { (decomp.) } & \text { " } & 63 \\ 4 & \mathrm{C}_{4} \mathrm{H}_{9} & \mathrm{C}_{10} \mathrm{H}_{14} \mathrm{O}_{4} \mathrm{~N}_{4} & 179 & \text { " } & 52 \\ 5 & \text { iso- } \mathrm{C}_{4} \mathrm{H}_{9} & \mathrm{C}_{10} \mathrm{H}_{14} \mathrm{O}_{4} \mathrm{~N}_{4} & 178 \text { (decomp.) } & \text { " } & 65 \\ 6 & \mathrm{C}_{6} \mathrm{H}_{13} & \mathrm{C}_{12} \mathrm{H}_{18} \mathrm{O}_{4} \mathrm{~N}_{4} & 147 \sim 148 & \text { " } & 52 \\ 7 & \mathrm{C}_{7} \mathrm{H}_{15} & \mathrm{C}_{13} \mathrm{H}_{20} \mathrm{O}_{4} \mathrm{~N}_{4} & 108 \sim 109 & \text { /" } & 41\end{array}$

\begin{tabular}{|c|c|c|c|c|c|}
\hline & & Analy & is $(\%)$ & & \\
\hline & Calcd. & & & Found & \\
\hline C & $\mathrm{H}$ & $\mathrm{N}$ & C & $\mathrm{H}$ & $\mathrm{N}$ \\
\hline 42.48 & 4.46 & 24.77 & 42.79 & 4. 46 & 24.85 \\
\hline & & 23.33 & & & 23. 31 \\
\hline & & 23.33 & & & 23.37 \\
\hline & & 22.04 & & & 21.83 \\
\hline & & 22.04 & & & 22.18 \\
\hline 51.05 & 6.43 & 19.85 & 51.30 & 6.68 & 19.71 \\
\hline & & 18. 91 & & & 19.02 \\
\hline
\end{tabular}

5-Nitro-2-furaldehyde 4-alkylthiosemicarbazone (Table IV) EtOH $50 \mathrm{cc} に$ 4-alkylthiosemicarbazide ${ }^{11,12)} 0.014 \mathrm{~mol}$ 执よび 5-nitro-2-furaldehyde diacetate5,6) $3.0 \mathrm{~g}(0.012 \mathrm{~mol})$ そ溶解. ついでこれに $15 \% \mathrm{H}_{2} \mathrm{SO}_{4} 30 \mathrm{cc}$ を加党水浴上に $1 \mathrm{hr}$ 還流加熱. 反応終了後, 冷却すれば目的化合物が析出. これを沪取, dil $\mathrm{EtOH}$ より再結晶.

Table IV. 5-Nitro-2-furaldehyde 4-Alkylthiosemicarbazone

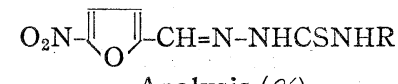

\begin{tabular}{|c|c|c|c|c|c|c|c|c|c|c|c|}
\hline \multirow[b]{2}{*}{ No. } & \multirow[b]{2}{*}{$\mathrm{R}$} & \multirow[b]{2}{*}{ Formula } & \multirow[b]{2}{*}{ m.p. $\left({ }^{\circ} \mathrm{C}\right)$} & \multirow[b]{2}{*}{ Appearance } & \multirow[b]{2}{*}{$\begin{array}{l}\text { Yield } \\
(\%)\end{array}$} & \multicolumn{6}{|c|}{ Analysis $(\%)$} \\
\hline & & & & & & & Calcd. & & & Found & \\
\hline & & & & & & $\mathrm{C}$ & $\mathrm{H}$ & $\mathrm{N}$ & $\mathrm{C}^{-}$ & $\mathrm{H}$ & $\mathrm{N}$ \\
\hline 1 & $H^{14 \sim 16)}$ & $\mathrm{C}_{6} \mathrm{H}_{6} \mathrm{O}_{3} \mathrm{~N}_{4} \mathrm{~S}$ & $>250$ & yellow needles & 91 & & & 26.16 & & & 26.21 \\
\hline 2 & $\mathrm{CH}_{3}$ & $\mathrm{C}_{7} \mathrm{H}_{8} \mathrm{O}_{3} \mathrm{~N}_{4} \mathrm{~S}$ & 220 (decomp.) & "I & 85 & 36.84 & 3.53 & 24.55 & 37.01 & 3.74 & 24.35 \\
\hline 3 & $\mathrm{C}_{2} \mathrm{H}_{5}$ & $\mathrm{C}_{8} \mathrm{H}_{10} \mathrm{O}_{3} \mathrm{~N}_{4} \mathrm{~S}$ & 180(decomp.) & 11 & 87 & & & 23.13 & & & 23.31 \\
\hline 4 & $\mathrm{C}_{3} \mathrm{H}_{7}$ & $\mathrm{C}_{9} \mathrm{H}_{12} \mathrm{O}_{3} \mathrm{~N}_{4} \mathrm{~S}$ & 169(decomp.) & 11 & 86 & & & 21.86 & & & 21.71 \\
\hline 5 & $\mathrm{C}_{4} \mathrm{H}_{9}$ & $\mathrm{C}_{10} \mathrm{H}_{14} \mathrm{O}_{3} \mathrm{~N}_{4} \mathrm{~S}$ & 153(decomp.) & $" y$ & 94 & & & 20.73 & & & 20.50 \\
\hline 6 & iso- $\mathrm{C}_{4} \mathrm{H}_{9}$ & $\mathrm{C}_{10} \mathrm{H}_{14} \mathrm{O}_{3} \mathrm{~N}_{4} \mathrm{~S}$ & 173(decomp.) & " & 81 & & & 20.73 & & & 20.82 \\
\hline 7 & $\mathrm{C}_{5} \mathrm{H}_{11}$ & $\mathrm{C}_{11} \mathrm{H}_{16} \mathrm{O}_{3} \mathrm{~N}_{4} \mathrm{~S}$ & 149(decomp.) & "1 & 86 & & & 19.71 & & & 19.43 \\
\hline 8 & $\mathrm{C}_{6} \mathrm{H}_{\mathrm{i} 3}$ & $\mathrm{C}_{12} \mathrm{H}_{18} \mathrm{O}_{3} \mathrm{~N}_{4} \mathrm{~S}$ & 128 & " & 82 & & & 18.78 & & & 18.70 \\
\hline 9 & $\mathrm{C}_{8} \mathrm{H}_{17}$ & $\mathrm{C}_{14} \mathrm{H}_{22} \mathrm{O}_{3} \mathrm{~N}_{4} \mathrm{~S}$ & $89 \sim 90$ & /" & 78 & & & 17.17 & & & 17.05 \\
\hline 10 & $\mathrm{C}_{10} \mathrm{H}_{21}$ & $\mathrm{C}_{16} \mathrm{H}_{26} \mathrm{O}_{3} \mathrm{~N}_{4} \mathrm{~S}$ & $95 \sim 96$ & " & 77 & 54.21 & 7.39 & 15.81 & 54.07 & 7.62 & 15.84 \\
\hline 11 & $\mathrm{C}_{12} \mathrm{H}_{25}$ & $\mathrm{C}_{18} \mathrm{H}_{30} \mathrm{O}_{3} \mathrm{~N}_{4} \mathrm{~S}$ & 101 & " & 90 & & & 14.65 & & & 14.39 \\
\hline 12 & $\mathrm{C}_{14} \mathrm{H}_{29}$ & $\mathrm{C}_{20} \mathrm{H}_{34} \mathrm{O}_{3} \mathrm{~N}_{4} \mathrm{~S}$ & 104.5 & $"$ & 86 & 58.50 & 8.35 & 13.65 & 58.66 & 8.38 & 13.54 \\
\hline
\end{tabular}

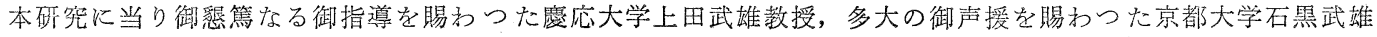
教授，鈴木友二教授に愿く感謝する。ぬた本研究に御援助を与えられた昭和薬品化工株式会社代表取䋨役長瀬 誠 博士，研究所長平野 保氏に謝意を表す。

14) E. Hoggarth : Brit. Pat. 620,888(1949).

15) O. Dann, E. F. Möller: Chem. Ber. 82, 76(1949).

16) R.F. Raffauf : Brit. Pat. 698, 271(1953). 